\title{
DOS POLOS DE ARTICULAÇÃO ÀS REDES DE RELAÇÕES - ENTREVISTA COM JULIO CEZAR MELATTI
}

\section{FROM THE POLES OF ARTICULATION TO THE RELATIONS NETWORKS - ENTERVIEW WITH JULIO CEZAR}

\author{
Entrevistadores: André Demarchi* \\ Odilon Morais** \\ Entrevistado: Julio Cezar Melatti***
}

\section{Apresentação ${ }^{1}$}

A conversa que se segue aconteceu na cidade de Carolina, no Maranhão. Mais especificamente no Centro Timbira de Ensino e Pesquisa Pënxwyj Hëmpejxà, onde acontecia o VI Seminário Temático Timbira, que naquele ano de 2015 contava com apresentações de pesquisadores indígenas e não indígenas. Melatti era um convidado de honra dos organizadores do evento. Eles proporcionavam o reencontro entre o pesquisador e alguns indígenas Krahô, que ali estavam para apresentar suas pesquisas, assim como o retorno do antropólogo à região onde fizera seu trabalho de campo para o doutorado, ainda na década de 1960.
0 material recolhido para sua tese sobre o "sistema social Krahô" (defendida na USP, em 1972) rendeu outras publicações, como os Ritos de uma Tribo Timbira e 0 Messianismo Krahô o primeiro, um clássico da etnologia brasileira que o autor fez questão de distribuir para os pesquisadores indígenas durante o Seminário.

Graduado em geografia e história, Melatti foi aluno do Curso de Especialização em Antropologia Cultural, organizado pelos professores Luis de Castro Faria e Roberto Cardoso de Oliveira, no Museu Nacional, na UFRJ, nos idos de 1960. Ainda doutorando, foi lecionar na $\mathrm{UnB}$, onde se aposentou depois de mais de três décadas dedicadas à pesquisa com povos indígenas

\footnotetext{
* Doutor em Antropologia Cultural pela Universidade Federal do Rio de Janeiro (UFRJ). Professor Adjunto da Universidade Federal do Tocantins (Tocatins/T0/BR). andredemarchi@gmail.com.

*** Professor da Universidade Federal do Tocantins (Tocatins/TO/BR). Doutorando em Antropologia Social pela Universidade de Brasília (UNB). odilonrmorais@gmail.com

*** Doutor em Antropologia pela Universidade de São Paulo (USP). Entre 1969 e 1994 foi professor na Universidade de Brasília (Brasília/DF/BR). Em 1997 pós-doutorou-se pela Smithsonian Institution nos Estados Unidos. Professor Emérito, Universidade de Brasília (UNB). juliomelatti@gmail.com.

1. Agradecemos à discente Francilene Medeiros Teixeira, do curso de ciências sociais, da Universidade Federal do Tocantins, pela transcrição do áudio dessa entrevista.
} 
(além dos Krahô pesquisou também com os Marubo), ao ensino e à divulgação da antropologia. Um dos temas de nossa conversa versou justamente sobre este último assunto: a criação e manutenção da "Página do Melatti”, o site na internet onde o pesquisador disponibiliza boa parte de suas notas de campo, genealogias de parentesco, contos de guerra e fragmentos biográficos dos índios Krahô além de artigos, resenhas e do seu seminal projeto sobre as "Áreas etnográficas da América Indígena”.

Este último projeto estava no centro do nosso interesse em conversar com Melatti. Foi inspirado nas “Áreas etnográficas" que criamos o projeto "Rede de relações indígenas no Brasil Central" 2 , muito influenciado pelas informações preciosas a respeito das redes de relações interétnicas contidas no capítulo sobre a área etnográfica "Tocantins -Xingu". A descoberta de um texto antigo de Melatti sobre os "polos de articulação indígena”, forneceu a chave metodológica para nosso projeto, possibilitando dimensionar em termos espaciais e temporais as redes de relações sociais, matrimoniais, cerimoniais, políticas tecidas por diferentes grupos indígenas entre si, ou mesmo, entre aldeias de um único grupo.

Participante ativo do Seminário, Melatti tomou muitas notas durante as falas dos pesquisadores. Quando, ao final do evento, foi convidado a encerrá-lo, nos brindou com as palavras transcritas no texto que se segue a essa entrevista. "Da antropologia como corrida de tora" é daqueles textos que já nascem clássicos, constituindo impor- tante material de introdução à disciplina a ser usado em cursos de graduação em ciências sociais. Além disso, é um texto produzido em diálogo intercultural que lança algumas respostas às incontáveis perguntas apresentadas pelos pesquisadores timbira durante o evento. É assim que gostaríamos de imaginar a leitura desses escritos, como um exemplo dessa antropologia que corre com toras.

Odilon Morais: Gostaria de iniciar a entrevista pedindo que você falasse da criação da Página do Melatti ${ }^{3}$.

Julio Cezar Melatti: A Página do Melatti tem esse nome porque eu queria fazer uma coisa minha. Porque eu, por exemplo, fazia a formatação do Anuário Antropológico e tinha que ouvir a opinião da comissão de escolha dos artigos. Então, quando eu deixei o Anuário Antropológico, pensei:agora vou fazer uma coisa minha (risos), a Página do Melatti. Aqui quem manda sou eu (risos). Foi mais ou menos essa a origem. Antes de a Página surgir, eu já ministrava esse curso sobre as áreas etnográficas da América do Sul e eu escrevia textos apressadamente para dar a aula, depois digitava e aí ele era mimeografado e eu distribuía na aula. Depois foi aparecendo a oportunidade de colocar na internet. Então eu fui passando para a internet. Primeiro aprendi a fazer o site em HTML, que era bastante ágil. Agora, recentemente, conforme começaram

2. 0 Projeto Rede de Relações no Brasil Central é desenvolvido no Núcleo de Estudos e Assuntos Indigenas (NEAI), da Universidade Federal do Tocantins. Seus primeiros resultados podem ser conferidos em DEMARCHI, A.; MORAIS, O. Redes de relações indígenas no Brasil Central: um programa de pesquisa. Espaço Ameríndio, v. 10, n. 2, p. 96-116, 2016.

3. É possível acessar a Página do Melatti no seguinte endereço: <http://www.juliomelatti.pro.br>. 
a aparecer telas de computadores que são mais compridas no sentido da largura e mais baixas no sentido da altura, as letras começaram a aparecer pequenininhas, e o texto encompridado. E também o HTML tinha um problema de não paginar, você mandava imprimir um texto e era corrido, se tinha uma figura no meio do texto ele cortava a figura. Assim resolvi fazer tudo em PDF. E além dos textos sobre as áreas etnográficas, comecei a colocar outros trabalhos antigos: resenhas, artigos, notas de campo. E assim a Página foi aumentando.

André Demarchi: Você sempre teve essa ideia de disponibilizar o seu material para o público?

Melatti: Sim. E mais recentemente, resolvi copiar as minhas notas de campo, selecionando trechos, editando um pouco. Já coloquei na Página mitos que não estavam publicados em lugar nenhum. Eu já coloquei dados sobre o massacre que os Krahô sofreram em 1940, que estavam espalhados nos meus diários de campo. Então, os juntei e fui fazendo coisas desse tipo.

Odilon: Você colocou também dados sobre a vida de alguns indígenas Krahô e também alguns dados biográficos sobre eles?

Melatti: Sim. E também as genealogias. Eu tenho todas as genealogias Krahô em folhas emendadas umas nas outras. Para relacionar um indivíduo com outro eu me perdia no meio. Aí, resolvi fazer as genealogias por casa. Comecei a ampliar aquelas feitas na tese e colocar outras figuras, e também adicionei a população Krahô por casa. Fiz uma espécie de CPF dos índios, atribuindo a cada pessoa um número. E comecei a incluir o que sabia sobre cada um. Então, tem uma lista de pessoas também. E esses dados parece que têm servido a outros pesquisadores. 0 Prof. Márcio Silva, com aquele seu projeto da máquina do parentesco, pôs um dos seus orientandos, o Carlos Paulino ${ }^{4}$, para trabalhar com esse material. Ele (Carlos Paulino) disse que já foi até os Krahô também para coletar mais dados e analisar os ciclos matrimoniais dentro desse programa de computador.

André: E é você mesmo que faz tudo na Página do Melatti?

Melatti: Sim! Sou eu que faço tudo! Faço os mapas, faço os esquemas de parentesco, essas coisas todas. 0 site só é pobre em imagem. Não tem imagem! Pois, para ter imagens, a gente tem que pedir autorização. Eu senti mesmo que ia ter problemas com imagens no site quando eu tentei arranjá-las entre os colegas para fazer uma edição recente e com fotos do meu livro Índios do Brasil ${ }^{5}$. Mas as imagens que me mandaram - eu não sei se foi por receio de lesar direitos de imagem - eram imagens em que os índios apareciam lá no fundo pequenininhos. Não adiantou muito, não é? Não usei as fotos.

Odilon: Tem alguns trabalhos que você publicou que não estão no site?

Melatti: É, não tem tudo lá não! Por exemplo, este livro ${ }^{6}$ que eu vou distribuir hoje

4. PAULINO, C. M. O. A rede Mehi: em busca das estruturas de troca e parentesco Krahô.2016. 178f. Dissertação (Mestrado em Antropologia Social) - USP, São Paulo, 2016.

5. MELATTI, J. C. Índios do Brasil. São Paulo: Edusp, 2007.

6. MELATTI, J. C. Ritos de uma tribo Timbira. São Paulo: Ática, 1978. 
para os pesquisadores indígenas não está disponível. A minha tese está. Mas o livro repete muita coisa da tese, ele não é igual à tese, mas expande a parte dos ritos. E tem muita coisa que eu pretendo fazer, mas eu não vou mandar digitar o livro, nem eu mesmo vou digitar. Eu tenho vontade de escanear o livro, mas para isso preciso de um pouco de paciência porque terei que escanear página por página e são trezentas páginas. É um pouco demorado. Eu escaneei o meu diário de campo, não para botar no site, mas para uso de um ou outro pesquisador. Agora, quando eu vejo a letra, eu penso: "ninguém vai entender essa letra”. Mas, enfim, está escaneado e eu posso ceder a quem quiser. Só tem que acostumar com a minha letra, que muitas vezes eu mesmo não entendo se a frase não me ajuda a dar o sentido (risos).

Odilon: Existe uma ausência importante na Página do Melatti que é o texto "Polos de articulação indígena” .

Melatti: Esse texto eu nem sei se tenho mais. Eu escrevi antes da difusão do computador no Brasil. Saiu numa revista da FUNAI chamada Realidade Indígena. Esse texto está lá nessa revista.

Odilon: Qual é a relação existente entre os conceitos de "polos de articulação indígena" e "áreas etnográficas”?

Melatti: As áreas etnográficas surgiram de um fracasso meu de não conseguir desenvolver o conceito de "polos de articulação indígena” (risos). A ideia de polos de articulação tal como está proposto nesse artigo, de você medir, quantificar as relações entre, por exemplo, duas sociedades indigenas, como os Krahô e Xerente, ou Krahô e Guajajara, você tem que conhecer muito dessas relações para conseguir fazer isso. Não tem nenhuma novidade neste texto. Eu tirei essa ideia daquilo que os geógrafos chamam "hierarquia de cidades”. Há um livro publicado pelo IBGE, de um geógrafo brasileiro, chamado Spiridião Faissol ${ }^{8}$. Ele apresenta uma hierarquia das cidades. Por exemplo, quando a gente pega um mapa do IBGE, a gente vê que existem cidades representadas por um pontinho preto, outras com uma bolinha maior vazia, outras com uma bolinha maior, mas com um pontinho no meio, outra que tem dois círculos em volta. Esta simbologia é construída de acordo com a hierarquia entre as cidades e tem várias maneiras de estabelecer essa hierarquia. Uma delas, por exemplo, pode ser a quantidade de ligações telefônicas realizadas. As pessoas que moram em uma cidadezinha pequena no interior do Paraná, quantas ligações elas fazem? Para que cidades do entorno elas ligam? Com certeza uma dessas cidade é mais procurada que outras. Então, ela se torna um centro ou um polo de articulação. Foi inspirado nessa ideia que eu quis trazer esse método para as questões indígenas. Então se um povo, ou mesmo uma aldeia, não tem xamã, onde que ele vai procurar um xamã? Em outra aldeia? Em outro povo? Onde vão procurar artigos comerciais como café, sal, miçangas? Em qual cidade? Ou ainda, onde eles vão procurar casamento? Com parceiros de que aldeia ou grupo étnico vão casar? $\mathrm{Ou}$ até poderiam surgir relações negativas: com quem esse grupo vai fazer guerra? A

7. MELATTI, J. C. Pólos de articulação indígena. Revista de Atualidade Indígena. FUNAI, n. 18. p. 17-28, 1979.

8. FAISSOL, S. (Org.). Urbanização e regionalização: relações com o desenvolvimento econômico. Rio de Janeiro: IBGE, 1975. 
ideia era essa, colocar no mapa essas relações, diferenciando-as com cores e linhas. No caso das linhas, quanto mais relações existissem entre um grupo e outro, maior seria a sua espessura. E no caso das cores, cada tipo de relação social estabelecida teria uma cor diferente.

Odilon: Você chegou a testar esse método com algum grupo indígena?

Melatti: Não cheguei. A ideia ficou só jogada nesse artigo. Eu achei mais cômodo, em termos metodológicos, ficar com as velhas áreas culturais, porque seria impossível realizar sozinho esse trabalho do mapeamento dos polos de articulação.

André: Estamos acompanhando aqui nesse encontro uma série de apresentações dos pesquisadores indígenas falando dessa mistura que existe entre os diferentes povos Timbira, e entre os povos Jê, de modo geral. Essa mistura é algo que a gente percebe muito presente também no seu material disponível na Página do Melatti, principalmente, nas histórias de vida de muitos Krahô. Quando começamos a ler essas notas biográficas que você produziu, percebemos a presença de relações de casamento e outras tantas com pessoas de outros grupos indígenas como os Xerente, Apinajé e até Kayapó. Eu gostaria que você falasse sobre essas relações interétnicas construídas pelos Krahô com outros grupos.

Melatti: Com certeza é algo que se percebe bem depressa. Basta estar em uma aldeia. A Terra Indígena Krahô tem uma forma que se aproxima muito toscamente de um losango. A parte norte é ocupada por certas aldeias e a parte sul por outras aldeias. $\mathrm{Na}$ parte sul estão os Mãkamekrá, os "filhos da ema": mã, significa ema; ekra, significa filho. É o povo que os cronistas chamam de
"Makamekrans", naqueles textos antigos. Eles moravam perto do rio Balsas no sul do Maranhão. 0 conflito com os fazendeiros, no final do século XVIII e começo do século XIX, empurrou os Krahô para a beira do rio Tocantins, para a região de Carolina. Era uma região onde um comerciante goiano se estabeleceu e fez amizade com uma parte dos Krahô, justamente os Mãkamekrá. Esse comerciante goiano escravizava outros índios que ele embarcava para vender em Belém. Então os Krahô se aliaram a esse comerciante e colaboraram nesta busca de escravos. Ele se chamava Francisco José Pinto de Magalhães e deu o nome ao lugar de São Pedro de Alcântara. Então, esse foi o primeiro nome de Carolina. Não sei quando é que mudou de nome, mas os cronistas que passam por lá na primeira metade do século XIX dizem que era um lugar horroroso que não tinha nada. 0 próprio Major Francisco de Paula Ribeiro fala que eles atraíram os índios para São Pedro de Alcântara e não tinha comida para dar aos índios. Chegou todo um grupo indígena, os Põrekamekrá, e passaram fome lá. Não tinha nada, não tinha boi, não tinha alimento vegetal, não tinha coisa nenhuma. Era realmente só um ponto de embarque de escravos. Lugar de pousar para descansar, mas quem descansava lá também não tinha muito o que comer. Foi assim o nascimento de Carolina. E depois, acho que em 1847, os Krahô já estavam incomodando os fazendeiros, porque eles acabaram de mandar os índios escravizados para Belém, não tinha mais nenhum por ali e aí os Krahô começaram a incomodar, porque matavam muito gado. Assim os fazendeiros conseguiram com que o Império enviasse um missionário para Carolina. Chegaram vários missionários Capuchinos italianos nesse período. Fazia parte da política indi- 
genista do Império civilizar os índios por meio dos missionários, afınal de contas, o império tinha a religião católica como oficial. Então, a maneira de integrar os índios na sociedade nacional era por intermédio das missões, e esse missionário italiano chamado Frei Rafael de Taggia subiu o rio Tocantins com os Krahô e foi estabelecê-los no aldeamento Pedro Afonso. Logo acima de Pedro Afonso ficava outra missão no rio Piabanha e se chamava "Tereza Cristina". Essa missão era habitada pelos Xerente. Então houve muito contato dos Krahô com os Xerente, desde a segunda metade do século XIX, e parece que esse contato permaneceu. Quando os Krahô saíram de Pedro Afonso e foram um pouco mais para o norte e estabeleceram-se ali perto do município de Itacajá, esse contato de certa forma continuou e alguns Xerente foram com os Krahô e se estabeleceram lá com eles, sobretudo nessa parte sul do território Krahô. Já na parte norte do território, Gilberto Azanha diz, baseado num pequeno trecho de uma memória do Major Francisco de Paula Ribeiro, que esses índios que foram atraídos, os Põrekamekrá, foram atacados pelos próprios brancos que os tinham atraído. Uma parte foi atacada, aprisionada e mandada como escravos para Belém, e a outra parte foi integrada aos Makamekrans (Mãkrare ou Mãkamekrá). Gilberto Azanha defende a ideia de que os Krahô são compostos de Mãkamekrá e Põrekamekrá; Até a tese do Júlio Cesar Borges ${ }^{9}$ chama os índios da parte sul do território de Mãkrare e os da parte Norte de Põrekamekrá. Eu não ouvi os Krahô fazerem tal distinção. $\mathrm{Ou}$ seja, parece haver influência do trabalho antropológico sobre os índios. Eles estão repetindo o antropólogo. E um antropólogo mais novo está reproduzindo essa repetição. É curioso isso. Nada ouvi sobre a existência de descendentes Põrekamekrá reconhecidos no meio dos Krahô; eles não lembravam mais disso. Nimuendajú fala de Mãkrare no sul da terra indígena Krahô e no norte, de Kenpokateyê. Mas eu, quando perguntava sobre os Mãkrare, os do sul diziam que sem dúvida eram os Mãkrare. Agora no norte da Terra Indígena eles diziam outras coisas. Por exemplo, o chefe da aldeia Cachoeira dizia que era Krutkateyê $\hat{e}^{10}$ e dava um outro nome também. 0 que acontece, na verdade, é que os índios do norte da Terra Indígena Krahô tinham na época uma relação constante com os Apànjekrá (os moradores da aldeia de Porquinhos, no Maranhão, a que chamavam de Canela). Então tem muito Apànjekrá ou descendente de Apànjekrános Krahô. E também tem entre os Krahô descendentes dos que sobraram do ataque que os fazendeiros fizeram a uma aldeia no Maranhão chamada Travessia ou Chinela, que eram os Kenkateyê. Nimuendajú, na parte inicial do seu livro The Eastern Timbira, descreve e fala um pouco sobre cada grupo Timbira. Embora saibamos que ele fala muito mais dos Canela da Aldeia do Ponto, ele faz também um apanhado sobre cada grupo Timbira. Quando ele chega nos Kenkateyê, ele diz

9. Borges, J. C.Feira Krahô de sementes tradicionais:cosmologia, história e ritual no contexto de um projeto de segurança alimentar. 2014. 346F. Tese (Doutorado em Antropologia Social) - PPGAS/DAN/UnB, Brasília, 2014.

10. Disse isso baseado em minhas lembranças, mas não achei nas minhas anotações o endosso para essa informação. Krutkateyê era uma denominação entre outras a que se referiam quando indagados sobre o nome dos Krahô do norte da Terra Indígena. 
que esse povo era uma mistura de Krahô com Apànjekrá. Assim, se eles eram uma mistura de Krahô com Apànjekrá, aqueles que conseguiram escapar do massacre e foram para os Krahô ou eram Apànjekra mesmo ou eram Krahô. Mas, enfim, eu conheci pessoas que devem ter vindo meninos, a julgar pela idade, dessa aldeia que foi massacrada em 1913. Entre eles estava um velho chamado Luiz Baú Akrêi, e estava também Pïtkwyi (esposa do chefe Ambrosinho) e mais outras mulheres velhas, que também estavam lá. Um dos meninos que, em 1913, escapou do massacre da aldeia dos Kenkateyê, chamada Travessia, em 1940 já era chefe de uma aldeia Krahô chamada Cabeceira Grossa. Ele morreu em um ataque que os fazendeiros fizeram a essa aldeia em 1940. Foi até uma coisa altamente traiçoeira. 0 fazendeiro de Carolina chamado Zeca Santiago deu um boi para eles matarem e comerem, fez com que a aldeia se juntasse e quando a aldeia se juntou ele atacou. E esse chefe Krahô que era o Luís Balbino, pediu para conferenciar com o fazendeiro. E quando estava conversando com o fazendeiro, um dos seguidores do fazendeiro o matou. Então tem Kenkateyê, Apànjekrá, Apinajé, Xerente, sem negar que haja descendentes dos Ponrekamekrá, ainda que não se lembrem. Como em todos os grupos Timbira, além de toda essa mistura, ainda tem as relações estabelecidas com os negros. Assim, por exemplo, Pedro Penõ, que era um dos chefes mais conhecidos entre os Krahô era filho de um Xerente. 0 pai dele era o Xerente Tsarankté. A mãe era filha de índio Krahô mas neta de um negro chamado Trukat. Esse negro era suspeito de ter matado o major Tito. 0 Major Tito era filho de um fazendeiro da cidade de Riachão (MA)com uma mulher Krahô. 0 pai não o levou para casa dele, deixou-o na aldeia. Ele foi criado na aldeia, depois o pai levou o garoto para educar na cidade. Ele ficou um pouco na casa do pai e trouxe um gado quando voltou para a aldeia de novo. Então ele se tornou um criador de gado dentro dos Krahô. Até tem documentada, pelo relatório do presidente de Goiás de 1873, a visita que ele fez à cidade de Goiás. 0 governo provincial tirou a quantia de tantos mil réis do tesouro para comprar presentes para ele e seus seguidores. E dali eles retornaram de novo para os Krahô. Agora dizem que foi o Trukat que matou o Antônio Tito, outros dizem que foi outro civilizado chamado Florêncio ou coisa assim, mas, enfim, o Trukat viveu nos Krahô e deixou filhos e netos. E o Pedro Penõ é descendente dele. Por isso, o Pedro Penõ tem ascendência Krahô, Xerente e negra. 0 major Chiquinho era da aldeia Cachoeira. Quando eu cheguei lá, a aldeia Cachoeira estava dividida em duas. Tinha uma chamada Lagoa e a outra era chamada (do ribeirão) Abóbora. 0 major Chiquinho dirigia a do Abóbora. Era velhinho, eu acho que nem dirigia nada, mas ele fora realmente o chefe ${ }^{11}$. E o major Chiquinho tinha o cabelo encarapinhado mesmo, cabelo branquinho, mas seguro na cabeça, não caía não. Ele dizia que o pai dele se chamava Mateus Coelho Perna. É outro negro, eu acho. Também lá na aldeia de Pedra Branca umas pessoas tinham o cabelo meio crespo. Havia uma mulher que tinha o apelido de Cafuz (cafuza). Ela estava relacionada a alguém que eu não conheci que era chamado de João Crioulo, que, pelo nome, devia ser negro também. Então, tem 
pelo menos essas três fontes africanas entre os Krahô. É uma mistura. Agora, do ponto de vista Krahô é todo mundo Krahô. Tanto é que todos eles falavam Krahô, e assim eram considerados, fazendo parte dos ritos e participando deles.

Odilon: Existem ritos que marcam essas diferenças étnicas?

Melatti: Só um que eu saiba! No rito do Pempkahàk há um momento em que os rapazes em iniciação estão reunidos na casa deles, na casa do Pempkahàk, que é uma casa de residência da aldeia. Não que eles morem lá, mas naquele momento do rito eles estão concentrados ali. Eles vão ser atacados ritualmente por uma das metades. Na frente da casa, os amigos formais dos rapazes de iniciação fazem uma barreira, segurando varas no sentido horizontal, para deter os atacantes. Na frente dos amigos formais, faz-se uma outra fileira de gente, que são os estrangeiros. Agora, quem são os estrangeiros? Os estrangeiros são Xerente, Canela, etc. que nasceram fora das aldeias Krahô, nasceram entre os Canela, nasceram entre os Xerente. Mas, filho de Xerente, filho de Canela, que nasceram entre os Krahô não ficam naquela fila. Não são mais Canela nem Xerente, são considerados Krahô.

Odilon: É uma forma de consanguinizar o estrangeiro?!

Melatti: Sim. Só os nascidos fora das aldeias Krahô, externamente ao grupo, é que são ritualmente estrangeiros. Os outros que já nascem entre os Krahô já são Krahô mesmo, ou seja, não são estrangeiros. Embora eles saibam perfeitamente quem é filho de Canela, quem é neto de Canela, filho de Xerente.

André: São interessantes esses fatos que você está contando. Eles apontam para uma imagem dos povos falantes de língua Jê, habitantes do Brasil Central, bem diferente daquela imagem que ficou marcada da etnologia Jê, de grupos fechados em si mesmo. Quando notamos toda essa pluralidade étnica que compõe os Krahô, assim como os próprios Canela, de acordo com o que professor Ricardo Canela ilustrou naquele mapa dos vários grupos presentes na aldeia Ràmkôkamẽkra, outra imagem surge, muito mais aberta à mistura, à interação e produção de redes de relações com diversos povos. Gostaria que você comentasse um pouco sobre essas imagens divergentes.

Melatti: Essas diferenças se dão também por uma questão de informação. Eu fui para os Krahô, ouvia falar o nome Krahô, então pensava que todos eram Krahô. Só com o tempo fui sabendo das coisas e fui percebendo essa pluralidade, essa mistura. E isso não acontece só com os Jê. 0 caso Marubo, por exemplo, também é significativo. Depois de algum tempo comecei a me dar conta de que eles eram uma reunião de vários grupos que sobreviveram, resistiram à penetração dos seringueiros. Ficavam na região do rio Javari que é fronteira com o Peru. 0 Javari tem dois afluentes, um é o rio Curuçá e o outro é o rio Itacoaí. 0 Itacoaí, por sua vez, recebe o rio Ituí. Então são os três rios que correm para o Javari. Essa região foi invadida por coletores de borracha, nos 30 anos finais do século XIX, a partir de dois pontos: pelo norte, eram os seringueiros brasileiros; e pelo sul, seringueiros, aliás caucheiros, como eram chamados, vindos do Peru. Ali os índios foram incorporados a turmas de coletores, ou foram mortos, restando apenas pequenos grupinhos. Quando vem a crise da borracha no ano de 1912, essas turmas sairam, porque não tinha mais sentido para eles 
ficar coletando borracha, pois não tinham como vender. E os índios ficaram de novo livres. Então, parece que houve um movimento de aglutinação desses grupinhos remanescentes, e dá para perceber isso. Eu percebi isso e disse em um artigo. Depois, outro antropólogo chamado Javier Ruedas - que é espanhol de nascimento, mas hoje é naturalizado norte-americano - pesquisou nessa região e confirmou que realmente são grupos diferentes.

André: 0 caso Marubo parece similar ao que acontece nos Ràmkômekra/Canela como estávamos falando.

Melatti: Sim. Com os Ràmkômekra e muitos outros grupos também. 0 que questiona a ideia de uma pretensa intemporalidade dos grupos étnicos. Isso não existe. Nunca teve grupo intemporal. Mesmo que um grupo se mantenha sem contato ao longo de séculos e séculos, ele jamais será imutável.

Odilon: Poder-se-ia então pensar essas aldeias e a formação desses grupos locais como polos de articulações indígenas?

Melatti: Com certeza. 0 que é curioso! 0 sistema de parentesco Marubo é um sistema Kariera do tipo australiano - não tem nada a ver com Austrália, mas o tipo é australiano - que funciona assim: bastam quatro seções para formar uma unidade fechada e autossuficiente para manter um sistema Kariera. No entanto, os Marubo têm quase vinte seções. Então, vem logo a pergunta: se quatro seções dão conta do sistema, por que as outras? Porque as outras vieram de outros lugares, onde constituiriam outras unidades (cada qual com quatro seções), e se articularam. Por exemplo, os Marubo diziam que sua língua era a dos Chaináwavo (uma seção já desaparecida no tempo de minha pesquisa). Mas os Chaináwavo não podiam falá-la sozinhos, pois tinham necessariamente de viver numa unidade com quatro seções. Um homem Chaináwavo tinha sua mãe numa outra seção que alternava matrilinearmente com a dele ao longo das gerações. Seu pai era de uma terceira seção, que alternava matrilinearmente com uma quarta, na qual esse homem deveria encontrar esposa. Possivelmente, a unidade que continha a seção Chaináwavo difundiu sua língua entre as outras unidades que, articuladas com ela, formou os Marubo.

André: 0 que você está achando desse evento que propõe reunir pesquisadores indígenas e não-indígenas para falar dos diversos povos Timbira?

Melatti: Eu estava escrevendo o que eu vou dizer no final. Certamente vão me chamar para falar e eu quero dizer uma coisa muito importante: uma reunião como essa seria impensável no tempo em que eu comecei a minha pesquisa com os Krahô. Não havia nenhum programa de apoio aos índios e também os índios não sabiam escrever. Entre os Krahô somente três índios que sabiam escrever. 0 Pedro Penõ era um, o Davi Pinto era outro e o Antônio da Silva era o terceiro. O Penõ escrevia bilhetes, até em Brasília eu recebi bilhetes escritos pelo Pedro Penõ. O Davi Pinto eu sei que ele tinha um livro escolar, de leitura bem elementar, de menino. E ele pegava aquilo para ler. Naquela época não chegava papel na região, nem na cidade. Então, por exemplo, eu tinha que levar papel. Se eu comprasse uns objetos para levar para o Museu, e precisava embrulhar para levar na viagem, era um custo achar jornal ou qualquer tipo de papel. Mesmo na cidade de Itacajá não tinha papel. Não chegava jornal, não chegava papel, não chegava nada. $\mathrm{Na}$ minha primeira etapa de pesquisa de campo, 
eram três leitores Krahô numa população de 520. Ou seja, não era nada!

André: Você acompanhou o processo de escolarização dos Krahô?

Melatti: Não! Eu não vou lá há 43 anos (risos). Aliás, se eles quiserem falar mal de mim que falem (risos). Brincadeira. Mas não acompanhei muito não. Eu fui estudar os Marubo e depois em 1983 eu parei de fazer campo. Com certeza eu devia ter voltado aos Krahô. Mas por uma série de motivos eu não voltei. Teria sido bom voltar. Eu mantinha contato quando algum grupo deles passava por Brasília. Pedia notícias, anotava algumas coisas, mas nada com profundidade não.

André: 0 que você pensa sobre o fato dos pesquisadores indígenas fazerem pesquisa sobre sua própria cultura?

Melatti: Penso que os Timbira estão fazendo o possível, no tempo deles e do jeito deles. 0 curioso é que eles estão começando justamente por onde nós acabamos, ou seja, a antropologia começa, no século XIX, estudando os outros povos parecidos com os Krahô e depois dos anos 1930 passa também a estudar as sociedades ocidentais, com os estudos de comunidade e os estudos sobre as cidades. Os pesquisadores indígenas parecem estar fazendo o caminho contrário. Estão começando a pesquisar as suas próprias comunidades e, assim, supomos que no futuro eles vão estudar a gente. 